\title{
Avaliação de Políticas e Programas de Segurança Alimentar e Nutricional no Brasil: uma análise a partir do Plano Plurianual (PPA 2012-2015)
}

\author{
Luciana Rosa de Souza ${ }^{1}$
}

\begin{abstract}
O tema Segurança Alimentar e Nutricional (SAN) tornou-se importante na agenda das políticas públicas brasileiras nos últimos anos. A gestão pública brasileira aprimorou-se muito com a implementação destas ações. Neste artigo, analisamos criticamente a política de SAN, em implementação no Brasil desde 2012. O estudo foi feito com base na relação planejamento versus execução orçamentária da política de SAN no Brasil, a qual sustentou-se na avaliação crítica do Plano Plurianual (PPA 2012-2015) que oferece um espectro do planejamento de médio prazo. Os avanços observados no planejamento desta política não foram suficientes para superar as falhas na alocação orçamentária, as quais foram evidenciadas pela análise da disponibilidade orçamentária alocada para cada programa que compõe a política de SAN. Apesar dos avanços observados no planejamento e execução da política de SAN no Brasil, ainda há necessidade de melhorias, especialmente no que concerne à questão orçamentária.
\end{abstract}

Palavras-chave: orçamento público, Plano Plurianual, política de Segurança Alimentar e Nutricional.

\section{Food and Nutrition Security Policies and Programs Assessment in Brazil: an analysis from thePlurianual Plan 2012-2015}

The theme Food Security and Nutrition has been important in the agenda of Brazilian public policies in recent years. Brazilian public administration has been learning a lot with the implementation of these actions. In this paper we analyze the Food Security and Nutrition Policy implemented in Brazil. The study was supported by the observation of planning versus budget implementing of Food Security and Nutrition in Brazil. This analyze was based on critic evaluation of "Plurianual Plan" (2012-2015), whose offer one spectrum of planning of public policies in medium term. The advances observed on planning of this policy weren't enough for overcome the faults on budget allocation, evidenced by budget available for each program that compose Food Security and Nutrition policy. In spite of the advances scrutinized on planning and implementation of this policy in Brazil, there is a lot of areas for improvement, especially regarding on the budget issue.

Key-words: public budget, Plurianual Plan, Food Security and Nutritional policy.

\footnotetext{
${ }^{1}$ Pós-doutora pela Universidade Livre de Berlim. Professora de Economia do Setor Público da Universidade Federal de São Paulo (UNIFESP), Campus Osasco, SP. E-mail: luciana.rosa@unifesp.br.
} 


\section{ENTENDER O CONCEITO PARA ANALISAR A POLÍTICA DE SEGURANÇA ALIMENTAR E NUTRICIONAL (SAN)}

O objetivo principal deste artigo é apresentar as características essenciais da política de Segurança Alimentar e Nutricional em anos recentes. Para tanto, partimos do conceito de Segurança Alimentar e Nutricional (doravante SAN) evidenciada no documento: The StateofFoodandAgriculture in 20132. Segundo estedocumento o conceito de SAN deve ser relacionado com o sistema alimentar, já que "food systems - from agricultural inputs and production; through processing, marketing and retailing to consumption - can promote morenutritious and sustainable diets for everyone" (Food and Agriculture Organization of the United Nations FAO, 2013, p. 4) [1]. Este documento foi produzido pela FAO para nortear objetivos e orientações gerais a serem perseguidas pelas políticas de SAN que estão sendo (e que virão a ser) implementadas em diversos países do mundo. A questão norteadora deste artigo é: a política brasileira de SAN conseguiu descontinuar seu processo histórico baseado em programas assistencialistas?

Uma política pública pode ser considerada assistencialista quando suas intervenções são insuficientes para promover a emancipação e independência dos beneficiários, em relação a esta política, ao longo do tempo. Considerando a política de SAN em específico, o assistencialismo vincula-se à promoção de programas que focam suas intervenções no alívio da fome no curto prazo (ações emergenciais) e possui reduzidas intervenções para superar a fome ao longo do tempo (ações estruturantes). Nestes termos, admitimos que uma política de SAN cujas ações estejam centradas em medidas emergenciais tem contornos assistencialistas.

De acordo com Salcedo [2], é muito difícil de se ter um direcionamento claro e objetivo para uma política de SAN, dado que a mesma engloba diversas dimensões da pobreza. Assim, um dos grandes desafios da política de SAN centra-se em sua gestão/execução em nível federal (ação interministerial), além da demanda por medidas que englobem os três níveis da federação (Governo Federal, Estados e Municípios).

\footnotetext{
${ }^{2}$ Oferecido pela Food and Agriculture Organization of the United Nations (FAO).
}

Utilizou-se o conceito referência da FAO [1] como parâmetro básico para investigar esta política, idealizada para o Brasil entre os anos 2012-2015. Escolheu-se este conceito de SAN pelo fato de ele ter sido validado por um organismo internacional. $O$ recorte temporal de 2012-2015 justifica-se por duas razões, a primeira relaciona-se com o fato de termos informações a respeito dos programas e respectivos orçamentos que compõe esta política no período. A segunda vincula-se à suposição de que o país teve condições de avançar no planejamento e implementação destas ações, uma vez que as mesmas vêm sendo executadas há alguns anos.

Ter clareza do conceito exato de SAN é imprescindível para refletirmos a respeito desta política, uma vez que sob este conceito agrupam-se programas e projetos públicos com formas de operação e de organização, objetivos e financiamento diferentes. Ressalvando que em nível federal, uma das características essenciais da política de SAN, a qual precisa ser superada, é a ausência de coordenação e articulação de programas, ou seja, a execução desta política exibe dificuldades de articulação interministerial [3].

Conforme a FAO [1], uma política de SAN deve edificar-se sob " $a$ 'multisectorial approach', complementary interventions in food systems, public bealth and education" (p. 12). Para a entidade, o sistema alimentar envolve pessoas, instituições e processos nos quais os alimentos são produzidos, processados e oferecidos aos consumidores. Para a FAO, a SAN deve considerar o sistema alimentar e suas especificidades já que existem conexões indiretas entre nutrição e sistema alimentar, quais sejam, renda, preços, conhecimento ou educação alimentar e nutricional, distribuição e manejo dos alimentos, dentre outros.

O documento da FAO apresenta o bom funcionamento do sistema alimentar como essencial na promoção de ações vinculadas à boa nutrição. $\mathrm{Na}$ integra "food system strategies recognize the social, psycological and cultural benefits that come from enjoying a variety of foods" (p. 11). Ao mesmo tempo, o documento afirma que as ações para reduzir a desnutrição (uma das faces mais graves da insegurança alimentar) dependem de programas multidimensionais que perpassem diferentes setores da gestão. Ainda segundo o documento "because the necessary interventions cut across the porffolios of several government institutions" (p. 12). Ou seja, para que uma política de SAN seja efetiva é preciso uma intervenção 
capaz de superar as barreiras da gestão unidimensional, focada em um único órgão executor de um programa.

Porque é essencial falar em nutrição? Este é um tema importante porque vivemos uma fase de transição nutricional na qual coexistem a tendência de ampliação da prevalência de pessoas com sobrepeso/obesidade $^{3}$ com a manutenção da prevalência de pessoas desnutridas ou com deficiências em micronutrientes em certas camadas da população. Em um cenário como este, a discussão a respeito da nutrição é imprescindível, já que a má nutrição é caracterizada tanto pela desnutrição e deficiência de micronutrientes como pelo sobrepeso/obesidade.

Ilustrando a problemática acima por meio de dados, em 2013 foi divulgada a pesquisa de Vigilância de Fatores de Risco e Proteção para Doenças Crônicas por Inquérito Telefônico ${ }^{4}$, a qual constatou que a prevalência de pessoas acima do peso no Brasil passou de 42,7\% em 2006 para 51\% em 20125, enquanto o percentual de obesos subiu de $11,4 \%$ para $17 \%$. Na média, a parcela de brasileiros com sobrepeso passou de 43\% em 2006 para 51\% em 2012. Mencionamos também, a título de exemplo, a Pesquisa Nacional de Demografia e Saúde da Criança e da Mulher (PNDS/2006), pesquisa que apresentou a situação de carências de micronutrientes no Brasil, e indicou que $17,4 \%$ das crianças e $12,3 \%$ das mulheres em idade fértil apresentavam hipovitaminose A e 20,9\% das crianças e 29,4\% das mulheres apresentavam anemia [4].

Para analisarmos as prerrogativas básicas da política de SAN é imprescindível usarmos a perspectiva multissetorial, já que esta pressupõe intervenções complementares no sistema alimentar, na agricultura, na saúde pública e na educação. A multissetorialidade existe "quando a partir de um objetivo de política pública identificam-se programas prioritários que são potencializados através de uma ação convergente" (p.

\footnotetext{
${ }^{3} \mathrm{O}$ excesso de peso e a obesidade constituem um dos problemas mais sérios tanto dos países ricos quanto dos emergentes. Em 2002, a Organização Mundial da Saúde (OMS) estimou em 250 milhões o número de obesos a nível mundial, enquanto que em 2025 deverão contabilizar-se 300 milhões, o que demonstra bem o problemático avanço a que se está a assistir. Contudo, esse aumento apresenta diferentes velocidades de progressão de país para país [acesso em 14 ago 2013]. Disponível no site. http://www.obesidade.info/prevalenciaobesidade.htm.

${ }^{4}$ Disponível no site:

http://www.brasil.gov.br/noticias/arquivos/2012/04/10/pesquisa-indicaque-quase-metade-dos-brasileiros-esta-acima-do-peso. Acesso em 14/08/2013.

${ }^{5}$ Disponível no site:

http://www1.folha.uol.com.br/equilibrioesaude/2013/08/1332766-parcelade-brasileiros-obesos-cresce-54-nos-ultimos-seis-anos.shtml. Acesso em $28 / 08 / 2013$.
}

853) [5]. O documento da FAO [1] enfatizou a essencialidade de intervenções integradas e multidimensionais para a boa execução das políticas de SAN.

A II Conferência Nacional de SAN (2004) a definiu como "a realização do direito de todos ao acesso regular e permanente a alimentos de qualidade, em quantidade suficiente, sem comprometer o acesso a outras necessidades essenciais, tendo como base práticas alimentares promotoras de saúde, que respeitem a diversidade cultural e que sejam social, econômica e ambientalmente sustentáveis" [6]. O conceito brasileiro de SAN é muito abrangente e possui natureza interdisciplinar, abarcando: acesso aos alimentos, práticas alimentares saudáveis e práticas sustentáveis de produção ${ }^{[7]}$.

Observando com mais profundidade o "atual" conceito de SAN apresentado pela FAO, em 2013, percebemos que a agricultura vincula-se diretamente com a disponibilidade e a oferta de alimentos. Ao passo que o sistema alimentar relaciona-se com o acesso, já que pressupõe solução de problemas de distribuição. Saúde e educação são diretamente relacionadas com o uso dos alimentos. Sendo assim, a despeito de "novos temas" terem sido levantados pela FAO, a base ainda permanece relacionada com "disponibilidade", "acesso" e "uso" dos alimentos.

Este artigo foi dividido em quatro tópicos. No primeiro apresenta-se a metodologia, no segundo descreve-se os programas (retirados do Plano Plurianual 2012-2015 [8]) que compõe a política de SAN e no terceiro discuti-se criticamente os dados orçamentários. Encerrando os três tópicos, algumas conclusões a respeito do tema são tecidas.

\section{O que avaliar em uma política de Segurança Alimentar e Nutricional (SAN)?}

Para responder à questão norteadora desta pesquisa, qual seja - a política brasileira de SAN conseguiu descontinuar seu processo histórico baseado em programas assistencialistas? - usamos a avaliação formativa da política de SAN, em nível federal, no período 2012-2015. Segundo Faria [9] uma avaliação formativa tem como um de seus objetivos identificar falhas de uma política social que esteja em implementação. Nestes termos, um dos propósitos deste artigo é analisar criticamente a política de SAN do 
período acima, procurando identificar possíveis falhas na sua concepção e execução.

A análise dos recursos orçamentários disponíveis é essencial para compreendermos a execução da política de SAN, já que são os orçamentos que materializam os programas em termos de execução. Neste sentido, é preciso considerar que existem intervenções de SAN em diferentes ministérios, tais como, Ministério da Educação e Cultura (MEC), Ministério da Saúde (MS), Ministério do Desenvolvimento Social (MDS), Ministério do Desenvolvimento Agrário (MDA), Ministério da Agricultura, Pecuária e Abastecimento (MAPA), Ministério da Integração Nacional (MIN), dentre outros. Para estudarmos o orçamento de SAN, usamos o Plano Plurianual (PPA 2012-2015) [8], posto que este reflete o financiamento da política no médio prazo.

O PPA é um instrumento de planejamento governamental de médio prazo. Ele está previsto no artigo 165 da Constituição Federal, e tem por função estabelecer diretrizes, objetivos e metas da administração pública para um período de 4 anos. Organiza as ações do governo em programas e é aprovado por lei quadrienal, a qual vige desde o segundo ano de mandato de um governo até o final do primeiro ano de mandato do próximo. No PPA constam os atributos das políticas públicas executadas, assim como as metas físicas e financeiras, o públicoalvo e resultados a serem oferecidos à sociedade. Por ser um instrumento de planejamento de médio prazo, o estudo do orçamento de SAN, presente no PPA, tornou-se essencial para apreendermos se $O$ planejamento desta política descontinuou com práticas assistencialistas.

Deste modo, a análise do planejamento e orçamento (via PPA 2012-2015) fundamentou-se nas dimensões de SAN expostas pela FAO [1], quais sejam: agricultura, sistema alimentar, saúde e educação. Para este intento, usamos a pesquisa descritiva e crítica, a partir do estudo de documentos oficiais tais como o PPA 2012-2015 e o The State of Food and Agriculture in 2013: food system for better nutrition. No próximo tópico, será descrito o estudo da política de SAN no Brasil recente.

$\begin{array}{lllr}\text { CARACTERÍSTICAS } & \text { GERAIS } & \text { DA } \\ \text { POLÍTICA } & \text { DE } & \text { SEGURANÇA } \\ \text { ALIMENTAR } & \text { E } & \text { NUTRICIONAL } & \text { (SAN) }\end{array}$

\section{PLANEJADA PARA O BRASIL ENTRE 2012-2015}

O estudo de caso das políticas de SAN no Brasil tem foco analítico nas quatro vertentes discutidas pelo documento da FAO [1], quais sejam, agricultura, sistema alimentar, saúde e educação. A apreciação cruzou informações de planejamento e orçamento identificadas em documentos que versam sobre a política de SAN. Nos subitens que se seguem apresentamos as especificidades desta política no Brasil recente.

\section{Planejamento e Orçamento da política de Segurança Alimentar e Nutricional (SAN) vinculados às dimensões Agricultura $\mathrm{e}$ Sistema Alimentar}

O primeiro programa de SAN vinculado à agricultura que apareceu no PPA ${ }^{[8]}$ foi a agricultura familiar, cujas ações ficaram centralizadas no MDA. O tema se desdobrou em quatro objetivos: 1) financiamento e proteção da produção; 2) garantia de preços e renda para a agricultura familiar; 3) assistência técnica; 4) e comercialização em mercados institucionais. Em termos orçamentários, este programa teve um orçamento disponibilizado de R $\$ 98$ bilhões $^{6}$ para o período 2012-2015, sendo as seguintes cifras por ano: em 2012 foi de R $\$ 22,6$ bilhões; em 2013 foi igual a 24,2 bilhões e entre $2014 / 2015$ foi equivalente a $\mathrm{R} \$$ 51,2 bilhões.

Um segundo assunto que engloba agricultura e sistema alimentar encontrado no PPA ${ }^{[8]}$ foi ainfraestrutura hídrica. A primeira meta do programa de irrigação focou na reformulação do marco legal da Política Nacional de Irrigação e na elaboração do Plano Diretor Nacional de Irrigação (este objetivo teve no Ministério da Integração Nacional o seu executor). A segunda vinculou-se à oferta de crédito e de seguro para ampliação das áreas irrigadas, sendo o MAPA o executor. O terceiro objetivo centrou no fortalecimento da pesquisa e inovação orientados para a agricultura irrigada, neste caso foi também o MAPA o executor. O quarto e último objetivo focou na viabilização de projetos públicos de irrigação já existentes, tendo no MIN seu responsável. Todos os programas para estimular a agricultura irrigada obtiveram um recurso

${ }^{6}$ Disponível no documento: Plano Plurianual (PPA) 2012-2015, com acesso pelo $\quad$ sítio: http:/ $/$ www.planejamento.gov.br/secretaria.asp?cat $=155 \&$ sub $=175 \& \mathrm{sec}=10$ \#\#paAtual. 
orçamentário de $\mathrm{R} \$ 6,2$ bilhões, sendo divididos em $\mathrm{R} \$$ 1,3 bilhão para 2012; R \$ 1,5 bilhão para 2013 e R \$ 3,3 bilhões para o biênio 2014-2015. O acesso à água potável é essencial na promoção da SAN tanto para o consumo humano como para o uso na agricultura. $\mathrm{O}$ tema oferta de água apareceu no documento com dois objetivos, os quais têm no MIN seu órgão executor. $\mathrm{O}$ primeiro objetivo é formular uma Política Nacional de Infraestrutura Hídrica, enquanto o segundo é aumentar a oferta de água em sistemas integrados, priorizando as regiões com déficit. Ambos os objetivos receberam um aporte de R\$14,1 bilhões para o período 2012-2015, sendo R \$ 3,4 bilhões para 2012, R \$ 3,4 bilhões para 2013 e R\$ 7,3 bilhões para o biênio 2014-2015.

A sustentabilidade da agropecuária, abastecimento e comercialização apareceu como um outro programa importante, o qual almeja ampliar a produtividade da agricultura no longo prazo. Este tema contou com oito objetivos, todos sendo executados pelo MAPA. São eles: 1) apoiar a comercialização de produtos agropecuários que compõe a pauta da Política de Garantia de Preços Mínimos (PGPM7); 2) prover mecanismos de prevenção ao risco de produção; 3) ampliar a oferta de crédito rural; 4) elaborar, executar e acompanhar as políticas públicas do agronegócio do café; 5) implementar e monitorar as ações do Plano de Desenvolvimento da Agricultura de Baixa Emissão de Carbono (ABC); 6) incentivar a agricultura orgânica e de outros sistemas sustentáveis; 7) fomentar o associativismo e cooperativismo rural e 8) modernizar a gestão do Ministério da Agricultura, Pecuária e Abastecimento. Este conjunto de oito objetivos focados no tema sustentabilidade da agropecuária teve um orçamento previsto de $\mathrm{R} \$ 227,6$ bilhões, sendo $\mathrm{R} \$$ 51,7 bilhões para 2012, R \$ 55,7 bilhões para 2013 e R $\$$ 120,1 bilhões para o biênio 2014-2015 [8].

A defesa agropecuária foi uma ação que emergiu com cinco metas, todas executáveis pelo MAPA. Estes objetivos focaram: 1) sanidade da produção, armazenamento e distribuição dos alimentos; 2) reestruturação, implementação e coordenação do Sistema Unificado de Atenção à Sanidade Agropecuária; 3) aperfeiçoamento dos processos operacionais de defesa agropecuária para abranger o

\footnotetext{
${ }^{7}$ A Política de Garantia de Preços Mínimos (PGPM) foi criada em 1966 e teve (tem) como objetivo central garantir preços mínimos para produtos agrícolas. Por meio da Política de Garantia de Preços Mínimos (PGPM) o governo intervém no mercado (comprando excedentes e financiando a estocagem) em situações nas quais os preços dos produtos sejam menores que o preço mínimo, o qual é definido pelo governo para produtos de safras regionais ou de safra de verão.
}

território nacional; 4) ampliação e qualificação da oferta de serviços laboratoriais para atender a defesa agropecuária; e 5) promoção da qualidade dos insumos agropecuários visando aumentar a produtividade e competitividade da produção. Estes objetivos tiveram um orçamento de R \$ 1,6 bilhão para todo o período, sendo R\$ 408 milhões para 2012, R \$ 393 milhões para 2013 e R\$ 841 milhões para o biênio 2014-2015 [8].

A temática da gestão de políticas para a agricultura foi contemplada no PPA 2012-2015 via programa de desenvolvimento territorial e economia solidária. Para aprimorar a execução da política de SAN, usou-se uma abordagem territorial, a qual propõe integrar políticas públicas setoriais e federativas, usando múltiplas escalas territoriais como base de ação. Todas as ações de desenvolvimento territorial localizam-se no MDA. A abordagem territorial tem como objetivos: 1) superar as desigualdades de renda, gênero, raça e etnia; 2) fortalecer as políticas voltadas para a inclusão produtiva e para a consolidação de redes socioeconômicas de agricultura familiar nos territórios rurais; 3) melhorar a infraestrutura territorial, consolidando a abordagem territorial como estratégia de desenvolvimento sustentável para o Brasil rural; 4) emitir documentação civil e jurídica, além de apoiar a participação das organizações de mulheres rurais nas instâncias colegiadas e nos comitês gestores de políticas.

Existem dois objetivos relacionados com o desenvolvimento territorial e economia solidária que ficaram sob a responsabilidade do Ministério do Trabalho e Emprego (MTE), quais sejam: 1) fomentar empreendimentos econômicos solidários e suas redes de cooperação em cadeias de produção, comercialização e consumo; e 2) fortalecer a institucionalidade da política nacional de economia solidária (a partir de sua articulação federativa), integrando as políticas de promoção das iniciativas econômicas solidárias. $\mathrm{O}$ conjunto de ações para promover o desenvolvimento territorial e a economia solidária obteve $\mathrm{R} \$ 37,5$ bilhões em recursos orçamentários no período entre 2012-2015, sendo R $\$$ 10,3 bilhões designados para 2012, R $\$ 8,5$ bilhões para 2013 e R\$18,5 bilhões para o biênio 2014-2015 [8].

Um programa importante é aquele que abarca o fomento à inovação agropecuária. Tal tema foi executado pelo MAPA e estruturou-se a partir de 4 objetivos, quais sejam: 1) pesquisar, desenvolver e transferir tecnologia para aumentar a competitividade e 
a produtividade da agricultura; 2) desenvolver tecnologias para sistemas agrossilvopastoris das regiões cacaueiras dos biomas da Mata Atlântica e Amazônia; 3) disseminar a cultura de propriedade intelectual no desenvolvimento da biotecnologia, da agricultura de precisão, da proteção de cultivares, da indicação geográfica e marcas coletivas; 4) atender as necessidades do pequeno e médio produtor. Este conjunto de quatro objetivos recebeu um aporte de $\mathrm{R} \$$ 2,6 bilhões para o período 2012-2015, sendo R $\$ 726$ milhões para 2012, R \$ 622 milhões para 2013 e R\$1,1 bilhão para 2014-2015 [8].

O acesso à terra é um ponto nevrálgico para a garantia da SAN, porque ao mesmo tempo em que afeta a oferta, abrange também o acesso aos alimentos. Neste tema, o PPA apresentou uma ação específica para tratar da reforma agrária e ordenamento da estrutura fundiária, com ações centradas no MDA. Esta temática contou com 5 objetivos, quais sejam: 1) melhorar o acesso às informações sobre a posse de terras via sistemas cadastrais e cartográficos do Instituto Nacional de Colonização e Reforma Agrária (INCRA); 2) identificar, discriminar e arrecadar terras devolutas com regularização fundiária das terras federais e estaduais, visando democratizar o acesso à terra ${ }^{8}$; 3) assentar famílias que componham o público-alvo da reforma agrária via compra de imóveis rurais, oferta de assentamentos com infraestrutura, oferta de crédito e licenciamento ambiental; 4) consolidar projetos de assentamentos sustentáveis, oferecendo financiamento produtivo, acesso aos mercados, agroindustrialização e assistência técnica para a autonomia socioeconômica das famílias; 5) proporcionar acesso à capacitação profissional e educação formal aos assentados da reforma agrária, povos e comunidades tradicionais e agricultores familiares beneficiários da regularização fundiária; 6) reduzir a violência no campo via mediação de conflitos agrários, prevenindo a tensão social no campo e garantindo proteção às famílias acampadas de trabalhadores rurais sem-terra; e 7) promover o acesso à terra a trabalhadores rurais via crédito fundiário para a aquisição de imóveis rurais e investimento em infraestrutura produtiva e social. Este programa teve aporte de R $\$ 11,2$ bilhões para o período em questão, sendo $\mathrm{R} \$ 3,3$ bilhões para 2012, $\mathrm{R} \$ 2,5$ bilhões para 2013 e R\$5,3 bilhões para o biênio 2014-2015 [8].

\footnotetext{
${ }^{8}$ Este objetivo prevê também a criação de condições simplificadas para imóveis rurais pequenos e médios e a promoção de direitos territoriais para as populações quilombolas, povos indígenas e outras comunidades tradicionais.
}

Acima apresentamos as medidas de SAN, planejadas no PPA 2012-2015, que tratam dos temas agricultura e sistema alimentar. No próximo subitem, será descrita a análise das ações específicas nominadas de programas de SAN.

\section{Os programas de Segurança Alimentar e Nutricional (SAN)}

No PPA [8] o programa de SAN teve como órgão executor principal o MDS. Foram estabelecidos três objetivos a serem executados pelo MDS e um a ser implementado pelo MS. Dentre os objetivos de responsabilidade do MDS estão: 1) consolidar circuitos locais de produção, abastecimento e consumo; 2) fomentar a inclusão socioeconômica de agricultores familiares, mulheres rurais, povos e comunidades tradicionais para abastecer mercados institucionais da rede socioassistencial; 3) estruturar a produção familiar e a inclusão produtiva de agricultores familiares, povos indígenas e comunidades tradicionais em situação de Insegurança Alimentar e Nutricional. Todos estes objetivos são estruturantes uma vez que almejam melhorar as condições de produção, oferta e distribuição de alimentos.

O acesso aos alimentos é uma meta que tem na transferência de renda uma forma importante para efetivar sua realização. Assim, o PPA 2012-2015 quando menciona o programa Bolsa Família enumera dois objetivos, ambos localizados no MDS. O primeiro foca na melhora das condições socioeconômicas das famílias pobres e extremamente pobres via transferência direta de renda. Já o segundo objetivo vincula-se com a localização e caracterização das famílias (público-alvo) dos programas de transferência de renda e de assistência social implementados pelo governo federal. Este último objetivo é diretamente relacionado com o subsídio ao planejamento e implementação de políticas de redução da pobreza e desigualdade social. O Bolsa Família no PPA 20122015 teve um orçamento empenhado de $\mathrm{R} \$ 90,3$ bilhões para o período completo, sendo R $\$ 21$ bilhões para 2012, R\$ 22 bilhões para 2013 e R $\$ 47$ bilhões para o biênio 2014-2015 [8].

\section{Saúde Pública}

Para o período entre 2012-2015, o PPA enumerou 12 metas a serem perseguidas pela política de saúde brasileira via Sistema Único de Saúde (SUS). Dentre estas 12 metas, entendemos que aquela que 
foca na vigilância em saúde possui conexão com as diretrizes de SAN, já que a alimentação é essencial na manutenção da saúde. A meta conectada com atenção à saúde da mulher e da criança, com o uso da Rede Cegonha para atendimento de populações em maior vulnerabilidade associa-se diretamente com a queda da Insegurança Alimentar e Nutricional, já que almeja reduzir a mortalidade infantil e os problemas gestacionais. O objetivo vinculado com a prevenção à saúde de pessoas idosas e portadoras de doenças crônicas pode ser indiretamente relacionado à SAN já que muitas doenças crônicas, como o diabetes ou a hipertensão, podem desenvolver-se devido a hábitos alimentares inadequados e ao sedentarismo ${ }^{[8]}$.

Um programa essencial para garantir o melhor aproveitamento biológico dos alimentos é aquele vinculado ao saneamento básico. $\mathrm{O}$ saneamento básico foi apresentado no PPA ${ }^{[8]}$ contendo um único objetivo a ser executado pelo Ministério das Cidades. Este objetivo foi centrado na implementação de medidas para melhorar a gestão em saneamento básico, compreendendo planejamento, prestação dos serviços, regulação, fiscalização, participação e controle social da oferta destes serviços. O programa de saneamento básico teve um orçamento previsto de $\mathrm{R} \$ 32,4$ bilhões para o período 2012-2015, sendo $\mathrm{R} \$ 10,8$ bilhões para 2012, $\mathrm{R} \$ 8,6$ bilhões para 2013 e $\mathrm{R} \$ 12,9$ bilhões para o biênio 2014-2015.

Sob a responsabilidade MS encontra-se o quarto objetivo, o qual relaciona-se com o tema alimentação saudável. Este objetivo visa controlar e prevenir doenças ocasionadas pela Insegurança Alimentar e Nutricional, e esta prevenção será alcançada por meio da Política Nacional de Alimentação e Nutrição (PNAN) ${ }^{[10]}$ que proverá a regulação dos alimentos e estruturará a atenção nutricional na rede de atenção à saúde. Por regulação dos alimentos entendemos a fiscalização da produção e distribuição de alimentos, além da fiscalização e punição da empresa alimentícia em relação ao uso de açúcares, gorduras e sal nos alimentos produzidos.

A atual PNAN (PNAN, 2012) ${ }^{[10]}$ possui nove diretrizes básicas, quais sejam: 1) organização da atenção nutricional; 2) promoção da alimentação adequada e saudável; 3) vigilância alimentar e nutricional; 4) gestão das ações de alimentação e nutrição; 5) participação e controle social; 6) qualificação da força de trabalho; 7) controle e regulação dos alimentos; 8) pesquisa, inovação e conhecimento em alimentação e nutrição; 9) e cooperação e articulação para a SAN. Segundo o documento, a PNAN fundamenta-se na SAN e no Direito Humano à Alimentação Adequada, tendo como uma de suas diretrizes o estímulo às ações intersetoriais com vistas ao acesso universal aos alimentos. Destacamos que apesar da PNAN ter tido um planejamento bem amplo, sua execução ficou penalizada pelo fato de não ter sido definido um orçamento específico para ela.

\section{Educação Pública}

Um dos programas mais importantes de alimentação no país é o Programa Nacional de Alimentação Escolar (PNAE), o qual em 2013 teve um orçamento de $\mathrm{R} \$ 3,5$ bilhões ${ }^{9}$ para atender a aproximadamente 44 milhões de estudantes da rede pública (nos níveis Federal, Estadual e Municipal) de ensino. Em 2012, os recursos destinados ao PNAE totalizaram $\mathrm{R} \$ 3,4$ bilhões, segundo informações oficiais do governo. Ressaltando que $30 \%$ do total de recursos ofertados pelo PNAE devem ser direcionados para a compra direta da agricultura familiar, logo, em 2013, o montante orçado para compra da agricultura familiar foi de $\mathrm{R} \$ 1,05$ bilhão.

Um dos grandes executores, no Brasil, do aspecto educacional que envolve a alimentação é o Fundo Nacional de Desenvolvimento da Educação (FNDE). Existem ações específicas de estímulo à produção orgânica e/ou criação de hortas escolares ${ }^{10}$, entretanto, não há orçamento arrolado para estas ações. Entende-se que as ações descritas no site oficial do FNDE são pontuais e não contemplam a complexidade e seriedade que o tema requer.

\section{ANÁLISE CRÍTICA: PLANEJAMENTO VERSUS ORÇAMENTO DA POLÍTICA DE SEGURANÇA ALIMENTAR E NUTRICIONAL (SAN)}

Neste espaço, segue a avaliação crítica da política de SAN refletida via PPA 2012-2015. Para isso, sumarizamos os programas executados por cada Ministério no Quadro a seguir. Esta foi a forma

\footnotetext{
9 Disponível no site: http://www.fnde.gov.br/programas/alimentacaoescolar/alimentacao-escolar-apresentacao. Acesso em 12/08/2013.

10 Disponível no site: http://www.fnde.gov.br/programas/alimentacaoescolar/alimentacao-escolar-alimentacao-e-nutricao e no site: http://www.fnde.gov.br/programas/alimentacao-escolar/alimentacaoescolar-acoes-educativas. Acesso em 12/08/2013.
} 
encontrada de identificarmos quais ministérios concentram maior número de ações. Em um segundo momento apresentamos uma tabela com os montantes empenhados $^{11}$ para cada programa e para o total da política de SAN no quadriênio 2012-2015.

O Quadro exposto foi suficiente para mostrar a prevalência de programas localizados no MAPA, com quatro programas. O MDS possui três programas, sendo um de ação partilhada com o MTE. Este quadro auxilia na identificação de pontos de desigualdade na alocação de responsabilidades de execução dos programas por Ministério. Já a Tabela a seguir é essencial para observarmos as desigualdades na alocação orçamentária.

Analisando os dados orçamentários exibidos na Tabela percebemos que $43,8 \%$ do orçamento de SAN previsto para o período 2012-2015 concentrou-se no MAPA. O MDA ficou com $27,04 \%$ do orçamento do PPA 2012-2015 e o MDS ficou com 19,8\%. Ou seja, $90,64 \%$ do orçamento para $\mathrm{SAN}$, presentes no PPA 2012-2015, concentrou-se em três ministérios. Os demais ministérios, como o MEC, Ministério das Cidades, MIN, dentre outros ficaram com o percentual restante. Esta alocação orçamentária concentrada já nos permite intuir a dificuldade desta política em ser transversal dentre os ministérios e em ser multidimensional.

Destaca-se que, no caso do MDS, o qual obteve alocação de 19,8\% dos recursos empenhados para SAN, o peso do Programa Bolsa Família nesta alocação é grande, já que representa 16,63\% dos recursos totais de SAN previstos no PPA 2012-2015. Sendo assim, apenas 3,17\% do orçamento do MDS poderão ser direcionados para as demais ações de SAN, incluindo o programa específico para SAN executado pela Secretaria Nacional de Segurança Alimentar e Nutricional (SESAN). Portanto, o problema na distribuição orçamentária se verifica tanto em âmbito interministerial como dentro dos próprios ministérios.

\footnotetext{
${ }^{11} \mathrm{Na}$ linguagem orçamentária quando mencionamos "empenho" estamos nos referindo a um recurso que o governo disponibilizou para um determinado programa. Quando é mencionado o termo "realizado" significa que o governo executou aquele programa que teve seu orçamento empenhado, e, finalmente quando observamos os termos "pago" ou "liquidado", significa que o governo pagou o programa que teve seu recurso empenhado. No caso em análise, o Plano Plurianual (PPA) trata apenas do "empenho" e não da realização orçamentária.
}

Primeiramente, é preciso esclarecer que, em 2011, 70\% 12 $^{12}$ da produção de alimentos brasileira foi proveniente da agricultura familiar, a qual tem no MDA seu representante institucional no Governo Federal. Assim, identificamos que os agricultores familiares, produtores de $70 \%$ dos alimentos consumidos pelos brasileiros, obtiveram um orçamento alocado de 61\% em relação àquele designado para a agricultura de exportação. Corroborando com este argumento citamos o documento da FAO [1], o qual expressa que "greaterefforts must be directed towards interventions that diversify small holderproduction".

Ainda reforçando este argumento, entendemos que a garantia do Direito Humano à Alimentação Adequada tem na reforma agrária sua principal ação, sendo seguida em ordem de prioridade, pela agricultura familiar. Vale a pena registrar que o atual governo vem apresentando um desempenho pífio no que concerne a reforma agrária. Dados divulgados por entidades de trabalhadores rurais sem terra mostraram que, em 2011, foram assentadas apenas 22.021 famílias $^{13}$, um número profundamente baixo se comparado com a média histórica imediatamente anterior.

Se formos analisar a rubrica que congrega recursos para a agricultura familiar percebemos que ela recebeu $\mathrm{R} \$ 98$ bilhões em recursos vis-à-vis $\mathrm{R} \$ 227$ bilhões recebidos pela rubrica que foca na sustentabilidade da agropecuária, abastecimento e comercialização. Ou seja, os recursos orientados para a agricultura familiar são 2,3 vezes menores do que aqueles direcionados para a agricultura de exportação. A rubrica sustentabilidade da agropecuária, abastecimento e comercialização direciona recursos diretamente à agricultura de exportação, uma evidência a isso é o fato de existir um objetivo vinculado diretamente a apoiar o agronegócio do café. O abismo fica ainda maior quando analisamos os recursos designados para a reforma agrária e ordenamento fundiário, que foram de $\mathrm{R} \$ 11$ bilhões, ou seja, 20 vezes menor do que aquele disponibilizado para a sustentabilidade da agropecuária, abastecimento e comercialização.

\footnotetext{
${ }^{12}$ Segundo informações disponíveis no site: http://www.brasil.gov.br/noticias/arquivos/2011/07/27/agriculturafamiliar-precisa-aumentar-vendas-e-se-organizar-melhor-diz-secretario. Acesso em 26/08/2013.

${ }^{13}$ Disponível em:

http://www.redebrasilatual.com.br/cidadania/2013/05/mst-entregacarta-exigindo-agilidade-de-reforma-agraria-7410.html. Acesso em 24/08/2013.
} 
O estudo do orçamento de SAN previsto no PPA 2012-2015 por temas/programas mostrou que o programa que foca na sustentabilidade da agropecuária, abastecimento e comercialização recebeu $41,92 \%$ do orçamento de SAN para o período. Ao passo que a agricultura familiar conseguiu $21,3 \%$ do total de recursos designados para os programas de $\mathrm{SAN}$, o tema reforma agrária obteve $2,07 \%$ do orçamento, enquanto o programa Bolsa Família teve 16,63\% do orçamento total disponibilizado para a SAN no período 20122015. O tema saúde (composto por oferta de água potável e saneamento básico) recebeu 8,58\% dos recursos orçamentários e o tema educação alimentar e nutricional (composto unicamente pelo PNAE já que os demais programas de educação alimentar não receberam uma rubrica específica no $\mathrm{PPA}$ ) recebeu apenas $0,64 \%$ do orçamento de SAN. O conjunto de temas/programas acima representam $91,14 \%$ do total de recursos alocados para a SAN.

A despeito de o país ter uma política de SAN que possui recursos orçamentários designados por lei, ela ainda desrespeita ações essenciais na garantia do Direito Humano à Alimentação Adequada (DHAA). De acordo com a OECD (2013) a efetivação do DHAA depende dos seguintes fatores: 1) reforma agrária; 2) agricultura familiar; 3) políticas de abastecimento; 4) vigilância sanitária dos alimentos; 5) e alimentação escolar. Entendemos que a reforma agrária e a agricultura familiar não receberam a alocação orçamentária por elas merecida no PPA 2012-2015.

Quadro. Sumário dos programas de Segurança Alimentar e Nutricional (SAN) distribuídos por Ministérios conforme Plano Plurianual (PPA) 2012-2015

\begin{tabular}{|c|c|c|c|c|c|c|c|}
\hline $\begin{array}{c}\text { Ministério } \\
\text { do Trabalho } \\
\text { e Emprego } \\
\text { (MTE) }\end{array}$ & $\begin{array}{c}\text { Ministério do } \\
\text { Desenvolvimento } \\
\text { Agrário } \\
\text { (MDA) }\end{array}$ & $\begin{array}{c}\text { Ministério do } \\
\text { Desenvolvimento } \\
\text { Social e Combate à } \\
\text { Fome } \\
\text { (MDS) }\end{array}$ & $\begin{array}{l}\text { Ministério } \\
\text { da Saúde } \\
(\mathrm{MS})^{14}\end{array}$ & $\begin{array}{l}\text { Ministério da } \\
\text { Agricultura, } \\
\text { Pecuária e } \\
\text { Abastecimento } \\
\text { (MAPA) }\end{array}$ & $\begin{array}{l}\text { Ministério } \\
\text { da } \\
\text { Integração } \\
\text { Nacional } \\
\text { (MIN) }\end{array}$ & $\begin{array}{l}\text { Ministério } \\
\text { da } \\
\text { Educação } \\
\text { (MEC) }\end{array}$ & $\begin{array}{c}\text { Ministério } \\
\text { das } \\
\text { Cidades }\end{array}$ \\
\hline \multirow[t]{4}{*}{$\begin{array}{c}\text { 1) Gestão } \\
\text { políticas para } \\
\text { agricultura }\end{array}$} & $\begin{array}{l}\text { 1) Agricultura } \\
\text { Familiar }\end{array}$ & $\begin{array}{l}\text { 1) Segurança } \\
\text { Alimentar e } \\
\text { Nutricional }\end{array}$ & $\begin{array}{l}\text { 1) Programa } \\
\text { Nacional de } \\
\text { Alimentação } \\
\text { e Nutrição } \\
\text { (PNAN) }\end{array}$ & 1) Irrigação & $\begin{array}{l}\text { 1) Acesso à } \\
\text { água }^{15}\end{array}$ & $\begin{array}{l}\text { 1) Programa } \\
\text { Nacional de } \\
\text { Alimentação } \\
\text { Escolar } \\
\text { (PNAE) }\end{array}$ & $\begin{array}{l}\text { 1) Saneamento } \\
\text { Básico }\end{array}$ \\
\hline & $\begin{array}{l}\text { 2) Gestão de } \\
\text { políticas para } \\
\text { agricultura }\end{array}$ & $\begin{array}{l}\text { 2) Programa Bolsa } \\
\text { Família }\end{array}$ & & $\begin{array}{l}\text { 2) Sustentabilidade } \\
\text { da agropecuária, } \\
\text { abastecimento e } \\
\text { comercialização }\end{array}$ & & & \\
\hline & $\begin{array}{l}\text { 3) Reforma Agrária } \\
\text { e reordenamento } \\
\text { fundiário }\end{array}$ & & & $\begin{array}{l}\text { 3) Seguro e defesa } \\
\text { agropecuária }\end{array}$ & & & \\
\hline & & & & $\begin{array}{l}\text { 4) Fomento à } \\
\text { inovação } \\
\text { agropecuária }\end{array}$ & & & \\
\hline
\end{tabular}

Fonte: Elaboração com base nos estudos efetuados no documento Plano Plurianual 2012-2015.

\footnotetext{
${ }^{14}$ Os programas executados pelo Ministério da Saúde - rede cegonha e prevenção a doenças crônicas - foram considerados por este Ministério como uma ação de segurança alimentar, entretanto, no Plano Plurianual 2012-2015 não há reconhecimento destas ações como vinculadas à Segurança Alimentar e Nutricional (SAN). Entendemos que as características básicas destas ações relacionam-se diretamente com ações de saúde, o que dificulta para qualificá-las como diretamente vinculadas à SAN (ou seja, elas são indiretamente vinculadas à SAN).

15 O Ministério da Integração Nacional ficou responsável por dois objetivos da política de irrigação, os quais foram incluídos na rubrica “acesso à água”.
} 
Tabela. Orçamento empenhado para cada programa de Segurança Alimentar e Nutricional (SAN) de acordo com o Plano Plurianual (PPA) 2012-2015

\section{Nome do Programa/Ministério executor}

Orçamento conforme Plano Plurianual (PPA) 2012-2015 (em mil R\$)

1) Gestão de políticas para agricultura (MTE e MDA)

$37.533 .544,00$

2) Agricultura Familiar (MDA)

124.811,00

3) Reforma agrária e ordenamento fundiário (MDA)

$11.258 .524,00$

4) Segurança Alimentar e Nutricional (MDS)

17.610.294,00

5) Programa Bolsa Família (MDS)

$90.334 .510,00$

6) Irrigação (MAPA)

6.248.641,00

7) Sustentabilidade da agropecuária, abastecimento e comercialização (MAPA)

227.679.752,00

8) Fomento à inovação agropecuária (MAPA)

1.643.263,00

9) Defesa agropecuária (MAPA)

2.679.191,00

10) Acesso à água (MIN)

14.156.751,00

11) Programa Nacional de Alimentação Escolar (PNAE/MEC)

$3.500 .000,00$

12) Saneamento Básico (Ministério das Cidades)

Total

543.191.969,00

Fonte: Tabela elaborada com base no Plano Plurianual 2012-2015.

Os dados apresentados na Tabela acima mostram que as ações de SAN totalizadas receberam, entre 2012 e 2015, um orçamento de R $\$ 543$ bilhões. Enquanto, a pesquisa divulgada pelo Conselho Nacional de Segurança Alimentar e Nutricional (CONSEA) [12], em 2011, afirmou que as ações de SAN, consideradas apenas para 2012, receberam um orçamento de $\mathrm{R} \$ 27$ bilhões [13]. No entanto, este mesmo documento oferecido pelo CONSEA apresenta uma contradição ao afirmar que "o OSAN16 (2012-2015)... considerando o montante disponível... teve seus recursos ampliados em 158\% entre 2004 e 2012, saindo de R $\$ 13,1$ bilhões para uma proposta de R\$ 33,8 bilhões em 2012”'. Ou seja, com base no documento do CONSEA (2011) é difícil identificar claramente qual foi o orçamento alocado para a SAN em 2012.

Focando o aspecto de educação alimentar e nutricional, os recursos mal aparecem no orçamento, algumas medidas se enquadram no programa de SAN, e outras no Fundo Nacional de Educação, que

${ }^{16}$ A sigla OSAN significa Orçamento da Segurança Alimentar e Nutricional. desenvolve hortas escolares e outras ações ${ }^{17}$. Além da PNAN (2012), a qual também não apresentou nenhum recurso orçamentário disponível. Nestes termos, este estudo apreendeu que, a despeito do acúmulo de experiências do Brasil no planejamento e execução das políticas de SAN, ainda há muito a avançar.

\section{CONCLUSÕES}

O tema SAN é essencial para a promoção de ações de combate à pobreza, à fome e à desigualdade. No entanto, ele centra-se sob um conceito complexo e multidimensional, o qual exige um planejamento e uma implementação difíceis. O conceito por si só não pode ser responsabilizado pelas dificuldades de gestão da política de SAN, já que a temática engloba interesses diversos que contemplam classes sociais diferentes, que lutam por objetivos múltiplos. Como exemplo citamos os agricultores familiares em sua luta por melhores condições de produções versus a agricultura de exportação. Sem considerar uma definição de SAN, é

\footnotetext{
17 Disponível no site: $\underline{\text { http://www.fnde.gov.br/fnde/sala-de- }}$ imprensa/noticias/item/4683-projeto-educando-com-a-horta-escolar-recebeinscri $\%$ C3\%A7\%C3\%B5es. Acesso em 24/08/2013.
} 
impossível analisar esta política e optou-se pela proposta da FAO pelo entendimento que ela ofereceu um conceito revisto e atualizado.

O estudo do PPA 2012-2015 ${ }^{[8]}$ mostrou que o planejamento da política de SAN ainda padece da centralização das ações em alguns ministérios, fato que ficou mais evidente quando observamos os recursos orçamentários disponibilizados. A análise dos recursos orçamentários mostrou uma desigualdade relevante na alocação orçamentária dentre MAPA versus MDA/MDS, e entre estes três ministérios e os demais. Por exemplo, o somatório dos percentuais de recursos direcionados para o MDA/MDS foi de $47,2 \%$, ou seja, apenas 3,4\% superior aos recursos disponibilizados para o MAPA (43,8\%). Ou seja, existe uma desigualdade na alocação dos recursos orçamentários para a política de SAN, a qual dificulta que as características de transversalidade e multidimensionalidade se tornem reais na implementação desta política.

Em relação à pergunta inicial deste artigo, qual seja, a política de SAN conseguiu descontinuar com o processo histórico centrado em ações assistencialistas, a resposta é que a descontinuidade foi total no que concerne ao desenho/planejamento da política, mas, foi apenas parcial no que concerne à sua implementação, observada pela análise do orçamento de SAN. Considera-se que ainda existe uma lacuna entre o planejamento e a execução de uma política. A análise crítica da alocação de recursos para a política de SAN explicitada pelo PPA 2012-2015 evidencia esta lacuna, já que muitas ações importantes para assegurar a ampliação da oferta de alimentos (em sua maioria produzida por agricultores familiares) recebeu menos recursos vis-à-vis a agricultura voltada para a exportação.

Pondera-se que, no que concerne ao planejamento da política de SAN, o país avançou de situações nas quais a política de alimentação era voltada para a entrega de cestas básicas de alimentos àquelas famílias em situação de fome, para uma política planejada para atender aspectos de curto prazo (fome), de médio prazo (garantia de produção e escoamento da produção realizada pelos pequenos produtores) e de longo prazo (voltada para a melhoria de produtividade e de escoamento na produção dos alimentos). Ou seja, em termos de planejamento (desenho) da política de SAN, certamente existiram avanços consideráveis. Entretanto, persiste uma lacuna, a qual não é privilégio da política de SAN, mas atinge várias políticas públicas no país, que é a implementação. Estas dificuldades de implementação guardam relação com problemas de gestão e dificuldades na alocação e execução orçamentária. Quando a política de SAN é analisada a partir do PPA 2012-2015, observa-se justamente esta lacuna entre o planejado e o que tem sido executado, tal lacuna pode ser percebida pela alocação de recursos financeiros.

Algumas considerações que o estudo do orçamento de SAN nos permitiu obter:

1) que houve uma priorização de medidas emergenciais (por exemplo, $16 \%$ do orçamento de SAN foi direcionado ao Bolsa Família);

2) que prevaleceu uma centralização orçamentária na agricultura exportadora, obtendo $43,8 \%$ dos recursos orçamentários disponíveis para a SAN;

3) que existe um orçamento insuficiente para a educação alimentar e nutricional (uso dos alimentos) e este orçamento não obteve alocação mencionada por nenhuma rubrica presente no PPA 2012-2015;

4) que há uma desigualdade na alocação de recursos já que a agricultura familiar, responsável por $70 \%$ da oferta de alimentos consumidos no Brasil em 2011, contou com um orçamento designado de apenas $21,3 \%$;

5) a reforma agrária, uma das ações mais importantes, a qual tem poder para ampliar a oferta de alimentos (no longo prazo) via agricultura familiar, recebeu um aporte de recursos de apenas 2,07\%;

6) ausência de um programa específico de educação alimentar e nutricional voltado para a redução da obesidade via mudança nos hábitos de consumo (redução no consumo de alimentos com alto teor de sódio/açúcares/gorduras);

Conclui-se que, a despeito dos avanços na política de SAN brasileira em anos recentes, esta ainda mantém limites relacionados à execução orçamentária. Tais limites fazem com que esta política priorize mais os programas de curto prazo (emergenciais) em detrimento aos programas de longo prazo (estruturantes). No início deste artigo, definiu-se que ao priorizar as medidas emergenciais, uma política pública assume traços de práticas assistencialistas. 
Assim, houve um predomínio de recursos alocados para a agricultura exportadora (43\% do orçamento total de SAN) e para medidas emergenciais (que focam na garantia de acesso aos alimentos, por exemplo, o Programa Bolsa Família obteve 16,63\% dos recursos de SAN) em detrimento de recursos alocados para ações que remetem ao longo prazo, tais como, a reforma agrária (que recebeu $2 \%$ do orçamento de SAN) e os programas de apoio à agricultura familiar. Este predomínio orçamentário, permite a conclusão de que a execução orçamentária da política de SAN ainda mantém alguns traços vinculados ao assistencialismo, já que o orçamento privilegiou ações emergenciais. No entanto, aponta-se que o planejamento desta política conseguiu descontinuar o processo histórico de ações assistencialistas. Ou seja, existe uma lacuna entre o que foi planejado para a política de SAN e o que vem sendo executado, e esta lacuna só foi percebida quando o orçamento de médio prazo para a política de SAN foi estudado. Logo, a análise do planejamento da política de SAN, via orçamento empenhado para cada programa, permitiu identificar algumas falhas presentes na execução orçamentária desta política.

\section{REFERÊNCIAS}

[1] Food and Agriculture Organization. The State of Food and Agriculture in 2013: food system for better nutrition. Roma [acesso em 15 jul 2013]. Disponível em: http://www.fao.org/publications/sofa/en

[2] Salcedo S. El marco teórico de la Seguridad Alimentaria. In: Políticas de Seguridad Alimentaria nos países de la Comunidad Andina. Santiago - Chile, FAO-RLC; 2005.

[3] Cunha ARA, Lemos MB, Nabuco MR, Pessoa MJ. Políticas locais de acesso alimentar: entre a regulação e as políticas compensatórias. In: BELIK W, MALUF RS. (Orgs.). Abastecimento e Segurança Alimentar - os limites da liberalização. Campinas, IE-Unicamp e CPDA-UFRRJ, 2000.

[4] Ministério da Saúde. Sistema de Planejamento do SUS: uma construção coletiva. Série: Cadernos de Planejamento, v. 9, Brasília, 2010.
[5] Burlandy L.A construção da política de Segurança Alimentar e Nutricional no Brasil: estratégias e desafios para a promoção da intersetorialidade no âmbito federal de governo. Ciênc Saúde Colet. 2009;14(3):851-860.

[6] II Conferência Nacional de Segurança Alimentar e Nutricional, "A construção da Política Nacional de Segurança Alimentar e Nutricional” - Relatório Final;2004.

[7] Kepple AW, Segall-Corrêa AM. Conceituando e Medindo a Segurança Alimentar e Nutricional. Ciênc Saúde Colet. 2011;16(1):187-199.

[8] Plano Plurianual 2012-2015 (PPA 2012-2015). Relatório de Comunicação Mista de Planos, Orçamentos Públicos e Fiscalização do Congresso Nacional (CMO) - Alterações do Plano Plurianual 2012-2015. Brasília, 2013 [acesso em3 ago 2013]. Disponível em: http://www.planejamento.gov.br/secretaria.asp?cat=155\&su $\underline{\mathrm{b}=175 \& \mathrm{sec}=10 \# \# \text { ppaAtual }}$

[9] Faria RM. Avaliação de Programas Sociais: Evoluções e Tendências. In: Avaliação de Políticas Sociais - uma questão em debate. São Paulo, Editora Cortez; 2009.

[10] Brasil. Ministério da Saúde. Secretaria de Atenção à Saúde. Departamento de Atenção Básica. Secretaria de Atenção à Saúde.Política Nacional de Alimentação e Nutrição. Brasília: Ministério da Saúde; 2012.

[11] Organization for Economia Co-operationand Development (OECD). Agricultural outlook 2013-2022 Executive Sumary, 2013 [acesso em 24 ago 2013]. Disponível em: http://www.oecd.org/site/oecd-faoagriculturaloutlook/

[12] Conselho Nacional de Segurança Alimentar (CONSEA). Alimentação, PLOA 2011 e dívida pública. Nota técnica n. 171. INESC, 2010 [acesso em 12 ago 2013]. Disponível em: http://www4.planalto.gov.br/consea/noticias/noticias/links Ldocumento-inesc

[13] Vigna E. Os desafios para o orçamento de SAN em 2012 [acesso em 12 ago 2013]. Disponível em: www.inesc.org.br 